\title{
Demand response behaviour of domestic consumers with photovoltaic systems in the UK: an exploratory analysis of an internet discussion forum
}

Eoghan McKenna* and Murray Thomson

\begin{abstract}
Background: Domestic consumers with photovoltaic (PV) systems in the UK can benefit financially by time-shifting their electricity demand to coincide with the output of the PV. This behaviour is a form of demand response and can provide insights into demand response behaviour more generally. This paper investigates whether people with PV in the UK engage in demand response, what appliances are used, and whether benefitting from free, self-produced electricity appears to influence their behaviour.

Methods: To achieve this, the approach presented here consists of an exploratory text analysis of an internet discussion forum frequented by consumers with PV in the UK.

Results: Data was gathered on 105 forum participants with PV, of which 45 mentioned engaging in demand response, for example by changing cooking or cleaning practices. Washing machines, dishwashers and electric space and water heaters were the most commonly used appliances for demand response. Six participants engaged in demand response and yet received no direct financial benefit from this behaviour, while 14 participants specifically mentioned the influence of free electricity.

Conclusions: The results illustrate novel demand response behaviour compared to previous studies and indicate that while price may be an effective initiator for demand response, there are additional factors beyond price that can enhance responses. The discussion considers the application of these factors to the development of innovative demand tariffs for low-carbon futures.
\end{abstract}

Keywords: Demand response; PV system; Domestic; Consumer; Behaviour

\section{Background}

Introduction

Demand response of domestic consumers to dynamic pricing

Demand response consists of consumers time-shifting electricity demand in response to some external signal, often in the form of a financial incentive [1]. This is commonly achieved by enrolling consumers onto demand tariffs with time-varying electricity pricing ('dynamic pricing'). There are different types of dynamic pricing [2],

\footnotetext{
* Correspondence: e.j.mckenna@lboro.ac.uk

Centre for Renewable Energy Systems Technology (CREST), School of Electronic, Electrical and Systems Engineering, Loughborough University, Leicestershire LE11 3TU, UK
}

and some of these are illustrated in Figure 1 and briefly described below.

Figure 1A shows 'time-of-use pricing', in this case, the Economy 7 tariff in the UK [3]. The day is divided into high and low prices periods, also called 'peak' and 'offpeak' periods. Time-of-use pricing is highly predictable the periods of high or low price do not change, and prices during these periods are known in advance.

Figure 1B shows an example of 'critical peak pricing', in this case, from the Ontario Smart Price Pilot [4]. Compared to time-of-use pricing, the day is divided into more periods, and there are more types of daily price profile. Critical peak pricing has been widely introduced by utilities in North America to help manage generation 


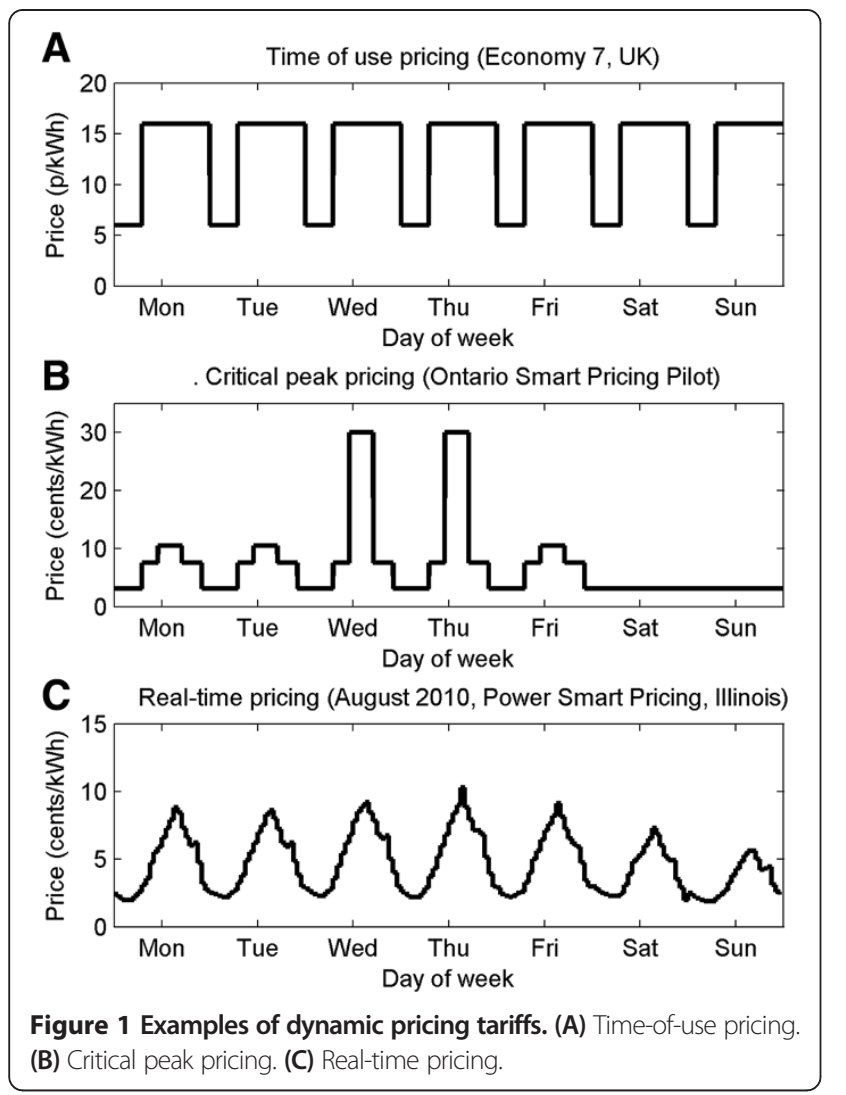

capacity shortages aggravated by high penetrations of air conditioning units [5].

Figure 1C shows 'real-time pricing', in this case, from the Illinois Energy Smart Pricing Plan. In contrast to the static predictability of time-of-use pricing, real-time pricing has prices that vary hourly, or sub-hourly, reflecting the variability of prices on the wholesale market [2].

Demand response of consumers to dynamic pricing is expected to play an important role in securing lowcarbon power systems in the UK [6-8], for example by helping to manage the intermittent output of renewables at national level, or by mitigating the impact of lowcarbon technologies such as electric vehicles at the level of the local distribution network [9]. As a consequence, there is a value in improving the understanding of demand response and, in particular, its social and behavioural aspects [1].

\section{Aims of the paper}

The aim of the paper is to develop an understanding of whether and how people with photovoltaic systems (PV) are engaging in demand response, and if so what factors affect this behaviour, thereby providing insight into domestic demand response behaviour more generally. To do this, the paper has the following research questions: Firstly, do people with PV in the UK engage in demand response and if so how (e.g., what practices and/or appliances are involved)? Secondly, does the fact that they can benefit from free, self-produced electricity appear to influence their demand response behaviour?

\section{Literature review}

Previous studies of demand response The increasing interest in demand response has resulted in a considerable number of dynamic pricing schemes in recent years. There are a number of publications that review the results of large numbers of such schemes; for example, Faruqui and Sergici [5] review 15 dynamic pricing schemes, predominantly from North America; Darby and McKenna [1] review the literature on dynamic pricing schemes with a particular focus on European schemes and the social aspects of demand response; while Stromback et al. [10] compare the results of 100 schemes from around the globe.

Several observations can be made from the above reviews. Firstly, the focus of dynamic pricing schemes is predominantly about quantifying the impact of time-of-use pricing or critical peak pricing on reducing peak demand, or reducing total demand. Looking forward, however, to future low-carbon power systems, there is value in understanding how consumers respond to price signals that are correlated with the output from intermittent generation from renewables, where prices might become less regular. Existing studies of demand response, however, do not provide insight into this area.

Secondly, while dynamic pricing evidently does produce a response from consumers in terms of peak demand reduction or total demand reduction, the above studies indicate that this response is limited, e.g., peak demand reduction ranging from $5 \%$ for time-of-use pricing to $16 \%$ for critical peak pricing [10]. There is also considerable variability between similar schemes, e.g., peak demand reduction in response to critical peak pricing ranges from 28\% in Australian schemes to $11 \%$ in Canadian schemes [10]. Consumer engagement has emerged as a key factor affecting the success of dynamic pricing schemes $[1,10]$, and this illustrates that while price is an important driver for demand response, there are additional factors beyond price that can have an important effect in terms of supplementing or maximising consumer response.

Finally, while there are a large number of existing demand response studies that focus on consumers with electric heating or cooling, particularly in North America and continental Europe, there are relatively few UK-based studies where the focus is on consumers without primary electric heating or cooling.

Variable effective electricity prices for grid-connected PV systems To provide insight, therefore, this paper 
investigates the 'demand response' behaviour of domestic consumers that occurs as a side effect of installing PV in the UK. This behaviour occurs because the value to the consumer of exporting electricity to the grid is typically four to five times smaller than the cost of electricity imported from the grid [11]. Consumers with PV therefore have a financial incentive to time-shift their use of electricity to whenever the PV is generating. They are, in a sense, engaging in demand response. For further information regarding PV and the feed-in tariff in the UK, see [12].

Indeed, similar to the way that conventional dynamic pricing tariffs encourage specific types of demand response behaviour, consumers with PV can be described as experiencing a variable 'effective price' of electricity that encourages them to shift their demand in relation to the times their PV system is generating. The effective price is determined by the dwelling's metering configuration, electricity tariffs (including any feed-in tariffs), and the instantaneous levels of dwelling demand and PV generation [13]. The effective price is a useful parameter, first, because it permits comparison with conventional dynamic pricing schemes and, second, because it may be regarded as the signal to which a 'perfectly rational' cost-optimising occupant of the dwelling should be responding to (assuming they are also the person paying the bill). A full description of the effective price can be found in the paper cited previously, while the following section summarises relevant parts of this work.

Figure 2 shows the PV generation, demand and resulting effective price over the course of a week in June 2006 for a $2.03 \mathrm{~kW}_{\text {peak }}$ PV system in the UK. In this case, the dwelling has a 'deemed export' metering configuration, which is the common metering configuration in the UK and relevant to the forum participants presented later. A deemed export system has a generation meter and an import meter, but no export meter, as shown in Figure 3. Exports are 'deemed' to be a fixed percentage (50\%) of what is generated. A fully metered system (not common in the UK), where an export meter has been fitted, is shown in Figure 3 for comparison.

The variable effective price has several characteristics that make it interesting for the study of demand response. Firstly, the price differential between high and low prices is not insignificant. The high, or 'ceiling', price is set by the import price, which is taken here to be $11.8 \mathrm{p} / \mathrm{kWh}$ (approximately $14.3 € \mathrm{c} / \mathrm{kWh}$ ) - typical for domestic consumer residing in the south east of England [14]. The low 'floor' price is set by the export price. For a deemed export system, the export price is $0 \mathrm{p} / \mathrm{kWh}$ as exports are not metered and so not remunerated. The range of prices is, in fact, quite similar to that of the Economy 7 tariff shown in Figure 1.

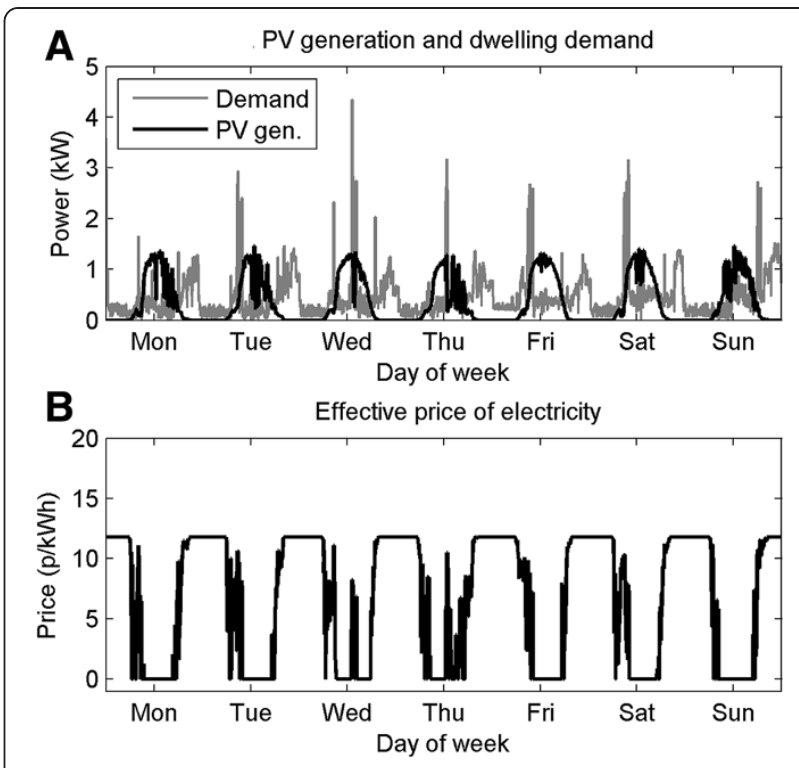

Figure 2 PV generation, dwelling demand and effective price. Data for 1 week in June 2006 for a $2.03 \mathrm{~kW}_{\text {peak }}$ PV system in the UK. (A) PV generation and dwelling demand. (B) Effective price of electricity.

Second, note that for consumers with PV in the UK with deemed export systems, electricity is free up to a limit set by the output of the PV system. The fact that electricity is occasionally free is again an unusual characteristic of the variable effective price and makes investigating demand response of consumers with PV in the UK of interest to the study of demand response more generally.

Third, the effective price shown in Figure 2 can be seen to fluctuate on occasion at a frequency that is comparable to the real-time pricing shown in Figure 1. The response of consumers to real-time pricing is of interest to engineers concerned with encouraging demand response in low-carbon futures $[15,16]$. Unlike traditional real-time pricing, however, the 'price signal' to which consumers with PV are responding is irregular as it depends on how brightly the sun is shining [13]. As a result, the availability of cheap electricity for the consumer will vary on a seasonal and daily basis in a complex, irregular way. Understanding whether domestic consumers with PV respond to this type of price signal therefore has additional value because it can provide insight into how domestic consumers might respond to real-time pricing in future low-carbon power systems, particularly those with high penetrations of solar power.

Fourth, note that where the consumer owns the PV system, they also own the electricity being produced by it, and they therefore can benefit from the possibility of consuming 'self-produced' electricity. This is again a novel feature of the variable effective price. 


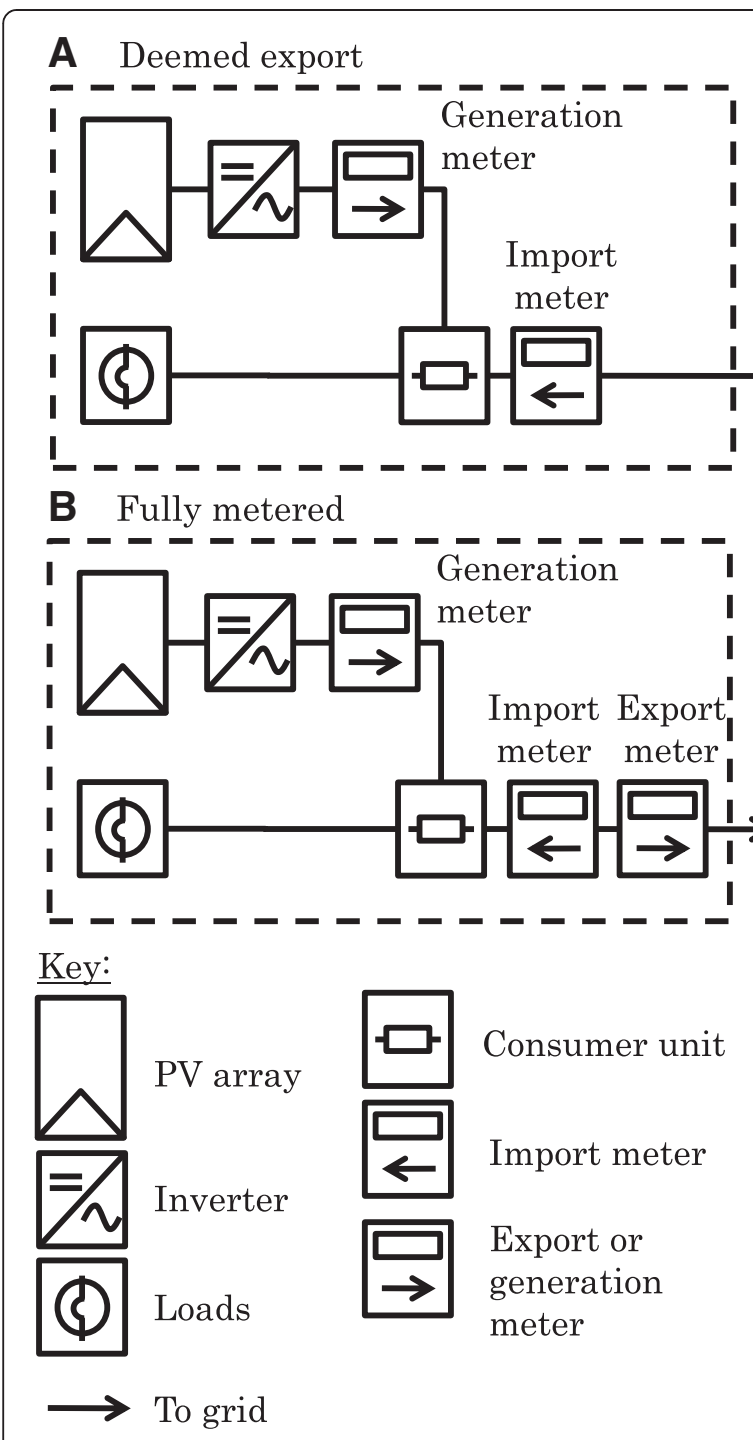

Figure 3 Two types of metering configurations for PV systems in the UK. A deemed export system (A) and a fully metered system (B).

Fifth, note that the effective price is determined, in part, by the dwelling's power consumption. The effective price is low provided that demand is kept below the output of the PV system and high if demand rises above the PV output. Figure 2 shows examples where demand exceeds PV generation, and the effective price can be seen to be high at these moments. The fact that the price is determined by the dwelling's power consumption in this way is quite unusual, and determining whether domestic consumers can understand and respond to such a 'power banding' tariff could aid in the development of innovative demand tariffs in the future.

Finally, note that the variable effective price is determined by the dwelling's metering configuration. The characteristics detailed above are valid for consumers with deemed export metering configurations, which is the common metering configuration for the UK. There are, however, some consumers with PV in the UK who have 'reversing import' metering configurations, as described in [13]. A reversing import metering configuration is one where exports to the grid wind back the import meter. Consumers with such configurations do not experience a variable effective price: their electricity price is always constant and determined by the import price of their standard demand tariff. As such consumers have no financial incentive to engage in demand response, and yet still have a PV system, they can provide an interesting group to compare behaviour with consumers with PV systems and deemed export systems.

Behavioural economics and demand response As indicated previously, while there is interest in understanding the response of consumers to dynamic pricing, there is also interest in exploring the effect of additional factors that can motivate demand response or otherwise 'nudge' consumers in the 'right' direction. The two of the characteristics of the PV variable effective price which are investigated here are the fact that electricity can be free and that it can be 'self-consumed', i.e., the consumers own the electricity that is produced by the PV and which they can then consume.

Behavioural economics offers a useful framework for improving the understanding of energy-related behaviour by considering 'irrational' consumer behaviour $[17,18]$. Research from this field suggests that these two characteristics could have an effect on consumer demand response behaviour, as described in the following sections.

The value of 'free' The value of 'free' describes a behaviour whereby people perceive the benefits of free (zero price) products to be greater than the benefits of the same products at low (non-zero) prices. For example, Shampanier et al. [19] contrasted the demand for two products across conditions that maintained the price difference between the products but varied the cost of the cheaper product between a low and zero price. As the price difference between the two products was maintained, the demand for the two products should not change, yet they found there was considerably more demand for the lower priced product when it became free.

Applying this theory to demand response, therefore, would indicate that while the price differential between high and low prices are similar between the variable effective price, and say, the Economy 7 tariff shown in Figure 1, the fact that the low price is free for the former would have a disproportionate effect and that consumers with PV would therefore be expected to engage more in demand response than if they were on Economy 7 tariffs. 
The endowment effect Furthermore, behavioural economics research has indicated that people value goods that they own more than goods that they do not [20], known as the 'endowment effect'. For example, Kahneman et al. [21] performed a laboratory experiment whereby subjects in a group were randomly allocated a mug. Subjects with a mug were then asked to state how much money they were willing to accept in exchange for the mug they had just been given, and the remaining subjects were asked to state how much money they would be willing to pay to receive a mug. The median willingness to accept was $\$ 5.75$, and the median willingness to pay was $\$ 2.25$. This asymmetry between willingness to pay and willingness to accept is known as the 'endowment effect' the simple act of conferring ownership of an item to a person alters the value they place in the item. Other studies have demonstrated loss aversion in the real-world, including sports card trading, the housing market, finance, labour supply and insurance [20].

The fact that consumers with PV own the PV system and therefore also own the generated electricity means that the endowment effect could potentially provide additional motivation for consumers to engage in demand response behaviour.

It would appear therefore that the effective price has characteristics that are of interest from a behavioural point of view. These can be viewed as factors that could affect demand response behaviour beyond the financial interest associated with the price differential between high and low prices.

Previous studies on behaviour of consumers with PV The previous sections have outlined the case for the value in investigating the demand response behaviour of consumers with PV in the UK. This section considers previous literature on the subject.

Keirstead conducted interviews with consumers of 63 dwellings with PV in the UK in 2005 [22]. The goal of the interviews was to investigate behavioural response to PV in the domestic sector. Though the overall focus of the interviews was on the possible conservation effect of PV, some of the questions were concerned with any time-ofuse changes made by the consumers. Forty-three percent of the participants described changes in the time that they used electricity, primarily associated with appliances such as the dishwasher or washing machine. Note that the focus of this paper is on the demand response effect of PV systems and not the potential effect of PV on demand reduction.

Bahaj and James discuss the value of time-shifting demand in dwellings with PV in the context of the potential 'added value' that PV systems can offer to consumers in fuel poverty in terms of reducing their electricity bills [23]. 'Load matching' is discussed to minimise exports and imports in order to obtain maximum value from the PV array. This is studied in terms of percentage figures for exported electricity to the grid. The findings were that low energy users receive less financial gain from PV systems than high energy users, principally because high energy users have higher baseload demand than low energy users. The study, however, did not indicate whether the consumers were responding to the PV by engaging in demand response.

Dobbyn and Thomas investigated how micro-generation affected attitudes and behaviours through interviews of consumers of dwellings that had various micro-generation technologies installed, including PV [24]. The focus of the study was mainly on whether the consumers were motivated to conserve energy after having micro-generation installed. Nonetheless, the study mentions how some interviewees had developed an understanding of which behaviours were 'free' or 'self-provided'. For example, one consumer with a micro-wind turbine mentioned that they turned on their electric heaters when the wind was blowing, presumably because they viewed this as free electricity. Washing machines are also mentioned being used by interviewees during times of peak output of microgeneration. Similar to previous studies mentioned above, however, the research does not focus on demand response behaviour in detail.

The present study differs considerably and builds upon the previous literature. This is the first study to investigate demand response behaviour of consumers which acknowledges: the specification of the variable effective price and how it is produced depending on the instantaneous levels of PV generation and demand, feed-in tariff and metering configuration; the explicit comparison between the variable effective price and conventional dynamic pricing and how the study of demand response behaviour of consumers to the former can yield novel insight into demand response more generally, in particular concerning into the additional factors beyond price that can motivate behaviour change.

For a broader discussion of this research, as well as a quantitative analysis of demand response of consumers with PV, and a discussion of the relevance of behavioural economics to the subject of demand response, see [25].

\section{Methods}

\section{Text analysis of an internet discussion forum}

In order to investigate demand response behaviour of consumers with PV in the UK, the approach was to analyse an internet discussion forum entitled 'So now I have a solar PV system how do I make the most of it?' on the website MoneySavingExpert.com [26]. The forum was started in January 2011 with the aim of providing a platform for consumers with PV in the UK to discuss tips and techniques for reducing electricity bills by making changes to 
behaviour. The forum is active, with over 180,000 views. Over 2,370 posts from this forum were analysed for this work.

\section{Benefits and limitations of approach}

One of the benefits of this approach is that it allows data to be captured from the field that is unbiased by a research context; the forum participants are freely contributing data without prompting from a researcher. Furthermore, analysing a large forum such as the one investigated here allows a large amount of data to be captured in a relatively short space of time; it can therefore be an efficient use of time and resources. An additional benefit is that the primary data, being an internet discussion forum, is publicly available which facilitates replication of the results or indeed future research based on the same primary data that builds upon the present work.

The limitations are that the researcher has no control over the content of the forum and as a result no control over its quality and relevance to the research questions. One of the consequences therefore is that analysis of this type is more suited to addressing research questions that are exploratory in nature and is less suited to formal statistical tests of behavioural hypotheses.

Another limitation is that the forum participants cannot be said to be representative of the UK population as a whole. Owners of PV systems, for example, tend to be older, more educated, richer and more likely to own their own home than the national average [27]. They are also more likely to be retired and occupy their dwellings during the day.

Furthermore, the forum participants are a self-selected group; not only are they early adopters of PV systems and the feed-in tariff, but in visiting a website called MoneySavingExpert.com, they are also evidently interested in developing an economic lifestyle and in contributing to the forum they are interested in learning about demand response behaviours that can result in cost savings.

This study does not therefore explore the prevalence of demand response behaviour in the population of PV owners in the UK but rather the behaviour of a selfselected sample of this population that is arguably economically minded and has already decided to engage in demand response. While it would not be valid to extrapolate the results to the broader population, the sample nonetheless serves as a useful case study to explore the behaviour of people that are on the more 'engaged' end of the spectrum of demand response.

\section{How the text was analysed}

To address the research questions, the following approach was used in analysing the forum text. Firstly, it was necessary to determine whether a participant actually had a PV system installed on their dwelling.
Information used to confirm this included mentioning of size of PV installation or installation date. Secondly, it was necessary to determine whether a participant engaged in demand response. This was determined by participants mentioning engaging in demand response behaviour, for example by mentioning use of appliances or practices in relation to PV output. Unique mentions of appliances or practices used when engaging in demand response were also recorded. The following quotation provides an example that demonstrates that the participant engaged in demand response as well as what appliances were used:

Great generating day today, best since mid-October. Managed 2 lots of washing, 2 tumble dryer loads, cooked lunch (electric hob), boiled kettle twice, pc on, $\mathrm{TV}$ on and had the oil heater at varying levels all day.

Next, it was necessary to determine whether the participants (with PV systems) experienced a variable effective price or not. The determining factor for this is their metering configuration. Participants with deemed export meter systems experience a variable price, while participants with reversing import meter systems do not. Participants that explicitly mentioned having a reversing import meter were assigned to the reversing import meter group, while the rest were assumed to have deemed export systems, as this is the default metering configuration for the UK.

Next, it was necessary to determine whether participant behaviour was affected by consuming free electricity. This was determined by quotations from participants that indicated that they recognised that their electricity consumption was free. The following quotations provide examples:

Today I had the luxury of using the tumble dryer for free. (J.P.)

I get great satisfaction out of seeing $3 \mathrm{~kW}+$ on the [monitor] and putting the kettle on for a nice brew for free :D (D.O.N.)

To determine whether participant behaviour was affected by consuming self-produced electricity, the approach was to find participants that engaged in demand response and yet had reversing import meters, meaning they received no direct financial benefit from doing so. One explanation for this behaviour is that these participants misunderstood the lack of financial benefit in demand response. Another possibility is that they were aware of the lack of financial benefit but still preferred to consume self-produced electricity. This could be explained with the endowment effect which would act 
to increase the value of self-consumed electricity over imported electricity. This is illustrated in the following quotations from a participant with a reversing import meter, who appeared to understand that there was no financial benefit in engaging in demand response behaviour and yet persisted in, and indeed enjoyed, this activity:

Actually I have [an importing meter] too. [...] Just realising though why my meter makes [a] difference. [...] I don't really have to save my jobs for a sunny day. [...] I do set the washing machine on timer through the week. (T.G.)

In a post 8 days later:

It is very difficult to [maximise self-consumption] although some of us have good fun trying. (T.G.)

In a post the following month:

On these very productive days I am struggling big time to use all the electricity I make. [...] We have turned off the gas heater and are using the immersion twice a day. (T.G.)

\section{Coding framework and derivation of results}

To provide a logical structure for the analysis, a coding framework was used as illustrated in Figure 4. Whenever a forum post was found that was relevant to the coding framing, then the post was tagged given the appropriate framing code, and an entry was made in a separate document against the contributor's forum alias, allowing for subsequent quantification of results. In total, relevant data was captured on 105 forum participants. All forum posts were read and analysed. The first post dates from the 2nd January 2011, while the last post analysed dates from the 24th April 2012. These correspond to the forum's first (initial) post and last relevant post at the time the research was conducted (May 2012).

The coding was performed by the principal author. The entire forum including all posts was saved as a Microsoft Word document, and the coding was performed using the same software.

To derive the results, Microsoft Excel was used to enter data against each forum participant. Each participant was assigned a row and variables (such as metering configuration, appliances used, etc.) were assigned to columns. The coded forum text was then used to populate the Excel work book, e.g., where a participant mentioned using an appliance for demand response a ' 1 ' would be entered against the relevant participant row and appliance column. These entries could then be used to quantify the results.

\section{Copyright and privacy}

The contents of the forum are owned by MoneySaving Expert.com and are protected by UK copyright laws [28]. The contents of the forum were used according to the website's terms and conditions: the use is non-commercial,

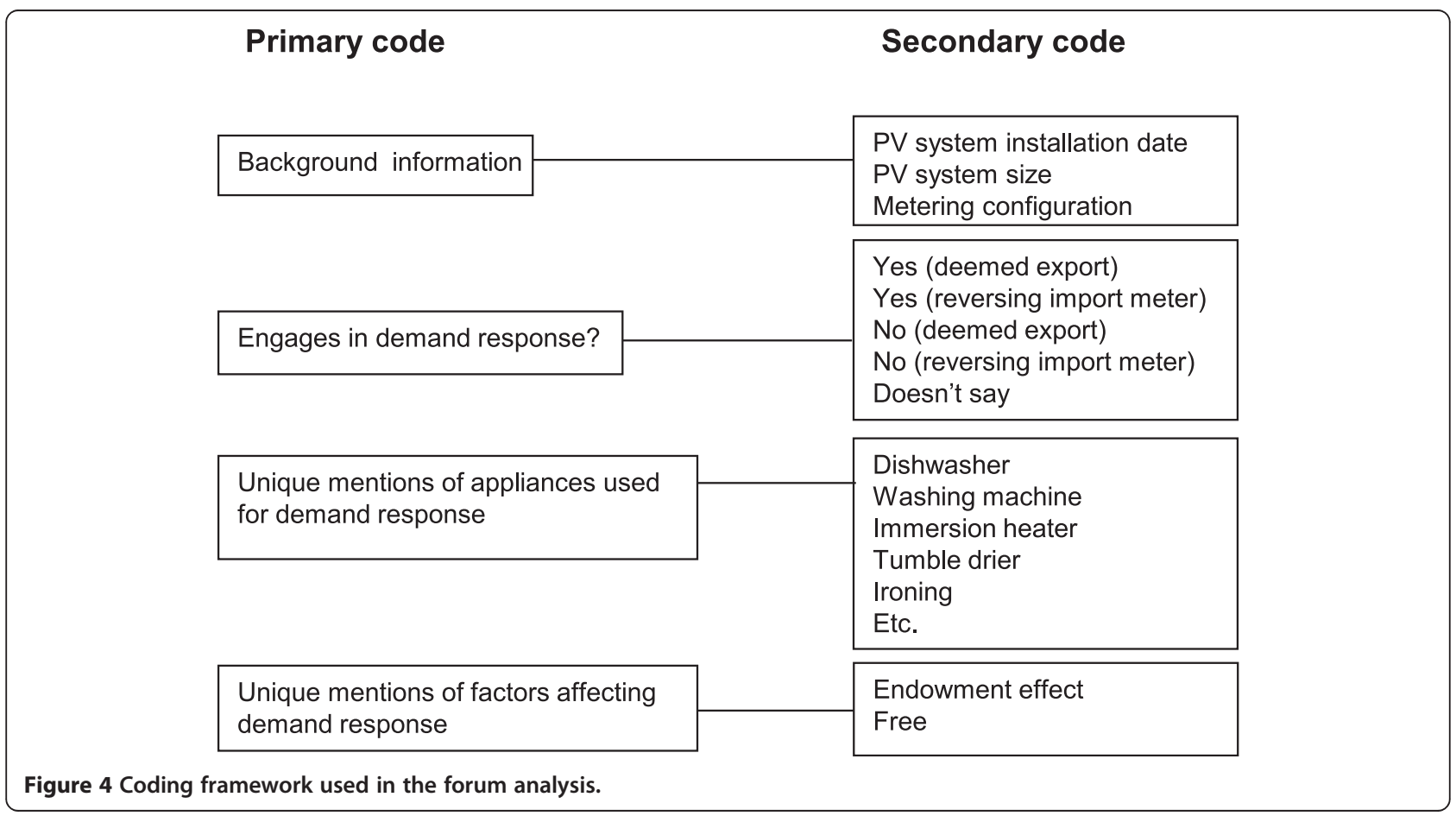


and a single copy of extracts from the discussion forum was made on a computer for personal, individual use only.

None of the data from the discussion forum can be classified as personal data, as it cannot be used to identify an individual. The participants use aliases when making posts, and furthermore the information that is on the forum has been knowingly made available to the public by the participants. Nonetheless, where data was collected on a participant, they were assigned an abbreviated alias, and any quotations that appear in the following are referred to using the abbreviation, not the participant's forum alias.

\section{Results}

\section{PV installation date and installed capacity}

Of the 105 participants, 47 stated the date of installation of their PV system. The distribution of dates is shown in Figure 5. All of the installations are after the start of the introduction of the feed-in tariff scheme (April 2010), and the assumption is made here that all of the participants are on a UK feed-in tariff. The number of installations has a peak towards the end of 2011, which can be explained by the reduction in the feed-in tariff generation price from $45.4 \mathrm{p} / \mathrm{kWh}$ (approximately $55.0 € \mathrm{c} /$ $\mathrm{kWh}$ ) to $21 \mathrm{p} / \mathrm{kWh}$ (approximately $25.4 € \mathrm{c} / \mathrm{kWh}$ ) that occurred at this time [11].

Figure 6 shows the distribution of installed capacities of PV systems as reported by 65 participants. The majority of installations are grouped near the $4 \mathrm{~kW}_{\text {peak }}$ threshold, which can be explained as installations over $4 \mathrm{~kW}$ peak have more complex connection arrangements, as well as lower feed-in tariff payments [29].

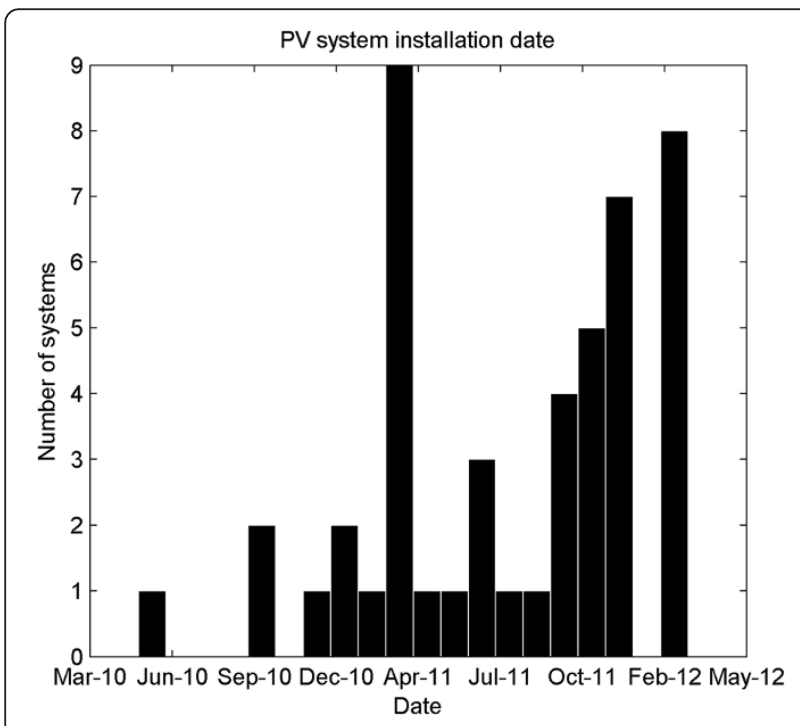

Figure 5 Installation dates of forum participant PV systems.

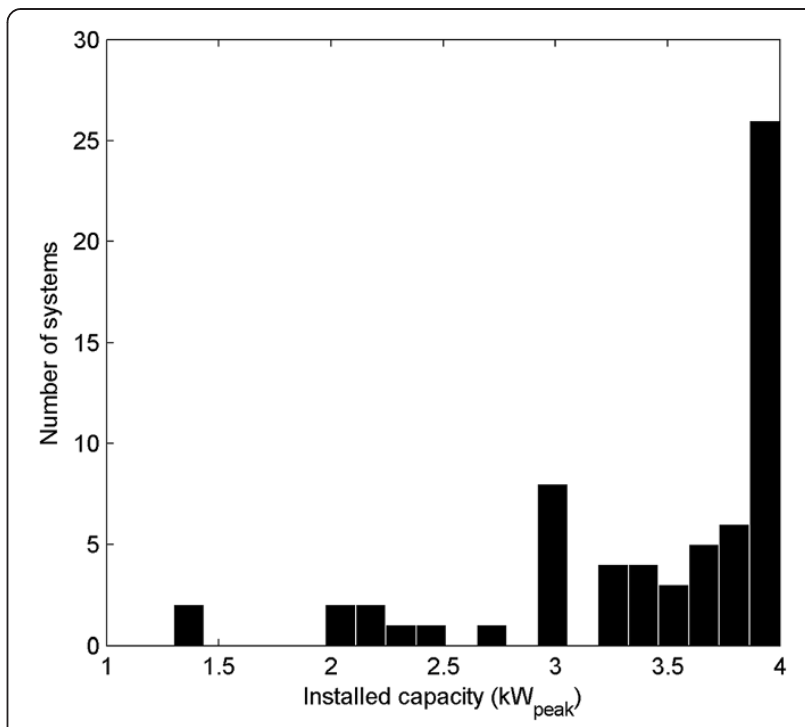

Figure 6 Size of PV system reported by forum participants.

\section{Metering configuration}

None of the participants mentioned having an export meter fitted, and it is likely therefore that all participants had 'deemed export' PV systems, as shown in Figure 3, where exports are not metered but deemed to be $50 \%$ of the electricity that is generated by the PV. All participants were therefore assumed to have deemed export systems with variable effective prices as described in the section 'Variable effective electricity prices for grid-connected PV systems', with the exception of 17 participants who reported that they had reversing import meters.

\section{Evidence of demand response behaviour}

Of the 105 participants, 45 (43\%) reported engaging in some form of demand response behaviour. These were participants who mentioned having engaged in timeshifting behaviour, for example by specifically mentioning that they used an appliance in order to benefit from the available PV generation.

Of the 45 who engaged in demand response, six reported having reversing import meters and so did not get any direct financial benefit from this behaviour. In this way, these six participants deviated from the 'perfectly rational' response either because they were misguided or because other factors affected their behaviour, as will be discussed in later sections.

Of the remaining 60 participants (57\%), 5 specifically mentioned that they did not engage in demand response and indeed all of these five had reversing import meters. The rest of the 60 did not mention engaging in demand response behaviour, but posted other relevant information, for example, the size of their PV system. This provides an indication of the level of interest in demand 
response behaviour of the forum participants insofar as they were motivated to post on the forum.

Out of the 45 who mentioned engaging in demand response behaviour, Figure 7 indicates the number of unique mentions of appliances that were used by the participants to engage in demand response. The following quotations provide examples.

Now (10:20) nudging $2.5 \mathrm{kw}$ so I'm running dishwasher - not quite 'free' as [the dishwasher] (in heating cycle) + base load exceed generation by $200 \mathrm{w}$ but still a lot cheaper than an E7 load. (E.R.I.)

[The monitor is] telling me I've got a surplus of almost $2 \mathrm{KW}$ so off to switch on washing machine. (E.R.I.)

\section{Appliance use for demand response}

The results of the present study has revealed considerably more appliances being used associated with demand response than reported in the previous literature on demand response behaviour of consumers with PV in the UK (section 'Previous studies on behaviour of consumers with PV'). As this is novel evidence of demand response behaviour, the following sections discuss some of the behaviours observed associated with these appliances.

\section{Washing machines and dishwashers}

The washing machine and dishwasher were the most commonly mentioned appliances used for demand response. Typically, participants mentioned switching on the washing machine and dishwasher during the middle of the day when their PV was generating, in order to take advantage of the cheap electricity offered by the system. The behaviour of the participants therefore agrees with the results of previous studies which also emphasise the use of 'wet' appliances for demand response [22,24].

Both the dishwasher and washing machine benefit from having a form of storage that enables people to be flexible in the times when they need to be used: dirty plates can be placed in the dishwasher, and dirty clothes can be allowed to build up in the laundry basket. Provided there were sufficient clean plates or clothes and sufficient space in the machines themselves, participants could be flexible about when the appliances were run. Participants were able to be more flexible with their dirty washing than their dirty dishes, for example, by mentioning that they saved their dirty washing for a sunny day but were less able to wait for a sunny day to clean dirty plates.

\section{Heating appliances}

Twelve participants had electric immersion water heaters and also had a year-round need for hot water. As a result, the conversion of PV electricity into hot water was mentioned by several participants as being a convenient method of using 'excess' or 'surplus' PV generation.

The best practical way to store surplus energy - in the sense of being able to utilise it when the sun isn't shining - is as hot water (O.G.R.)

The problem that some participants had was that their existing immersion heater was a $3-\mathrm{kW}$ device which, when switched on, would typically draw some, or most, of its electricity from the grid. As a result, some participants mentioned purchasing custom-built $1 \mathrm{~kW}$ immersion heaters,

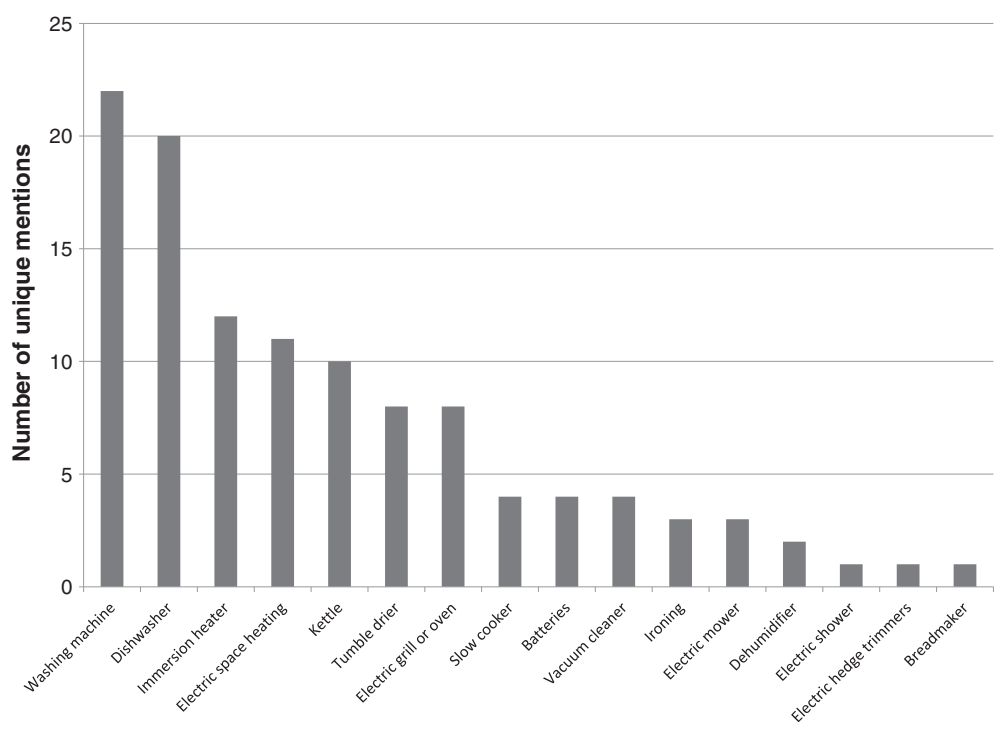

Figure 7 Number of unique mentions of appliances used for demand response by participants. 
which were less likely to import power when switched on. The low-power immersion heater is an example of a 'PVfriendly' appliance: a low-power version of an appliance that would be less likely to import power from the grid.

Other participants mentioned using PV electricity to power electric space heaters, usually in the form of portable oil-filled or radiant heaters. Small portable electric heaters seemed to be convenient to participants particularly if they had multiple power settings and were typically mentioned being used in the autumn or spring, as a replacement for gas central heating.

\section{Cooking appliances}

Participants also mentioned changing how or when they cooked meals. Some simply moved their hot meal from the evening to lunchtime, in the hope of running their electric grill or oven when their PV generation was high. Others mentioned cooking during the day and re-heating the meal using a microwave oven in the evening. 'Slow cookers' were also mentioned as PV-friendly due to their relatively low power consumption compared to conventional electric ovens.

Participants also replaced conventional 2 to $3 \mathrm{~kW}$ kettles with PV-friendly low-power 500 W 'travel kettles', particularly during the winter months. The following is a quotation from a participant regarding the use of a lowpower kettle:

I do of course realise that a $500 \mathrm{w}$ kettle for $12 \mathrm{mins}$ is using exactly the same as a $3 \mathrm{kw}$ one for 2 mins. As I wrote that, my Wattson meter was telling me I had a $500 \mathrm{w}$ excess so the little kettle cost absolutely nothing to run, the bigger one would have been working at ' $17 \%$ off'. [...] Other things being equal, I'm happy to wait a few minutes for a slow kettle rather than paying 0.06p (or whatever) for the instant gratification of a hot drink before I've had time to prepare the sandwich to go with it. Do that 150 times (and I'm sure I would most months) and there's a pound less on the next electricity bill. (E.R.I)

This quotation reveals that the participant was aware that the benefit of being more flexible in this case was very small indeed (0.06p), and yet they were still content to make considerable changes: sacrificing 'instant gratification' for the long-term prospect of reducing the bill at the end of the month.

\section{Behavioural factors affecting demand response}

Six out of the total of 45 participants who engaged in demand response were doing so and yet had reversing import meters, meaning they received no direct financial benefit from the behaviour. As discussed in section 'How the text was analysed' here, this has been taken as evidence of the endowment effect and that consuming self-produced electricity affected the participant demand response behaviour.

Fourteen out of 45 participants appeared to find pleasure in the fact that self-consumed electricity was free. As discussed in section 'How the text was analysed', this is taken as evidence that the consumption of free electricity provided an additional motivating factor that affected the demand response behaviour of the participants.

\section{Discussion}

\section{Power banding tariffs}

The investment of consumers in PV-friendly appliances such as low-power immersion heaters or kettles is a novel observed behaviour for consumers with PV, not reported in previous literature, and additionally provides evidence of consumers understanding and responding to a 'power banding' tariff: the price is cheap provided that demand is kept within a capacity limit determined by the PV generation. An important result of this paper is that even though this type of power banding tariff is quite complicated, it was nonetheless understood by the forum participants.

It is conceivable therefore that similar power banding tariffs could be used in future low-carbon power systems, for example by linking the variable capacity limit with the generation of local or national renewables resources. Given this paper's findings, it is conceivable that domestic consumers can be expected to understand such tariffs. It stands to reason that gaining such understanding is a useful first step in terms of encouraging demand response.

\section{Response to prices correlated with variable output of renewables}

Another finding is that consumers with PV are aware of, and respond to, a price that is correlated with the output of their PV system and, by extension, their local solar resource. This is a response based on an association between a variable price and a variable renewable resource. Response of this type will be of considerable value in future low-carbon power systems with high penetrations of renewables, and so there is a value in having found the evidence for this type of behaviour in the forum participants. It is important, however, to point out that the consumers with PV analysed here are responding to prices correlated with a local renewable resource, while consumers in future low-carbon systems may need to respond to the renewable resource at a national scale.

\section{Beyond price: developing innovative future demand response tariffs}

In keeping with the concept of the endowment effect, the forum participants did seem to enjoy the concept of producing and consuming their 'own' electricity. Indeed, this may have been a contributing factor that motivated 
some of the participants to engage in demand response behaviour even when they had no financial benefit in doing so.

The concept of producing your own electricity being a pleasurable thing was also suggested by the work by Dobbyn and Thomas in their interviews with owners of micro-generation [24]. The concept of ownership of electricity can help explain a lot of the enthusiasm for smallscale renewables like PV systems, and it also possibly provides additional motivation for consumers with PV to engage in demand response behaviour.

Looking forward to a future low-carbon power system, the endowment effect could possibly be harnessed at a community scale, for example by offering consumers living near wind farms an electricity tariff with power banding that is linked to the output of the wind farm. Not only could this be useful for potentially avoiding wind farm constraints but it could also foster community goodwill and perhaps facilitate planning permission for the development.

When goods become free, it can have a disproportionate effect on demand. The forum participants had the opportunity to consume electricity at zero cost, and indeed it appeared that some of them expressed satisfaction in this.

Free electricity is not something that is normally associated with dynamic pricing - prices may end up being quite low during some periods but never free. Yet, while the concept of free electricity may seem improbable in present markets, it might be less so in future markets with high penetrations of renewables. For example, models of the GB electricity market with high penetrations of wind indicate that wholesale electricity prices may fall to zero and even become negative at times [30,31].

Furthermore, there appears to already be a considerable amount of wind power that is constrained or curtailed in the UK and Ireland [32,33]. As penetrations of wind power increase, it is conceivable that instead of constraining wind power, consumers located near the wind farms could equally be paid to increase demand or at least benefit from free electricity.

The prospect of free electricity would provide a fundamental shift in how consumers would perceive the financial benefits of adopting dynamic pricing and this would be of value given the reluctance of consumers to adopt dynamic pricing $[34,35]$, particularly for tariffs that are complicated [36]. Moreover, the prospect of (limited) free electricity could help to mitigate the possible adverse impacts that future dynamic pricing tariffs might have on the fuel poor and help address equity implications of dynamic pricing [37].

In summary, it would seem therefore that while price is an important motivating factor for encouraging flexible demand in domestic consumers, there are ways in which we can go beyond price. Indeed, the factors that have been identified here are in fact well known to the behavioural sciences and are commonly used to influence consumer behaviour in other markets. Ultimately, this indicates that demand response behaviour is similar to other forms of consumer behaviour, insofar as it is open to being influenced by a wide range of factors beyond price, and this considerably expands the range of techniques available for developing future tariffs and securing demand response in low-carbon futures.

\section{Conclusions}

This paper's research questions were as follows: firstly, do people with PV in the UK engage in demand response and if so how (e.g., what practices and/or appliances are involved)? Secondly, does the fact that they can benefit from free, self-produced electricity appear to influence their demand response behaviour?

A text analysis of an internet forum frequented by consumers with PV in the UK indicated that the forum participants understood and engaged in demand response with respect to an electricity price signal that was correlated with the output of a local renewable resource. While this group is not representative of the broader population, nonetheless, this study provides evidence to support the assumption that domestic consumers can be expected to engage in demand response in low-carbon futures.

While washing machines, dishwashers and heating appliances were most commonly used to shift demand, there was also evidence of the shifting of practices which are not commonly associated with demand response such as cleaning and cooking practices. This indicates that domestic consumers can be more flexible than is perhaps commonly thought in the electricity supply industry.

The results of the study also suggest two factors that appear to influence participant demand response behaviour: first that self-consumed electricity was free and that it was self-produced and therefore owned by the participants. These factors are already familiar to the behavioural sciences and are readily applied in marketing. This paper has argued that these factors could be used to develop innovative demand tariffs in the future and that this could expand the range of techniques available to secure demand response in low-carbon power systems.

\section{Competing interests}

The authors declare that they have no competing interests.

Authors' contributions

EM conceived of and designed the study; gathered, analysed and interpreted the data and drafted the manuscript. MT critically reviewed the design of the study, the analysis and interpretation of the data and the manuscript; acquired funding for the study and read and approved the final manuscript. 


\section{Acknowledgements}

This work was supported by Secure Meters (UK) Ltd. and the Engineering and Physical Sciences Research Council, UK, within the HiDEF Supergen project (EP/G031681/1), the Transformation of the Top and Tail of Energy Networks project (EP/I031707/1) and the Realising Transition Pathways project (EP/K005316/1).

\section{Received: 1 November 2013 Accepted: 29 April 2014} Published: 20 June 2014

\section{References}

1. Darby SJ, McKenna E (2012) Social implications of residential demand response in cool temperate climates. Energy Policy 49:759-769

2. Albadi MH, El-Saadany EF (2008) A summary of demand response in electricity markets. Electric Power Systems Research 78:1989-1996

3. McCartney Al (1993) Load management using radio teleswitches within NIE. Power Engineering Journal 7:163-169

4. Strapp J, King C, Talbott S (2007) Ontario Energy Board Smart Price Pilot final report: prepared by IBM Global Business Services and eMeter Strategic Consulting for the Ontario Energy Board. Ontario Energy Board, Ontario

5. Faruqui A, Sergici S (2010) Household response to dynamic pricing of electricity - a survey of the empirical evidence., SSRN Working Papers Series, February, pp 1-59

6. Ofgem (2010) Demand Side Response (2012) A discussion paper. Accessed on 10th December. Available from: https://www.ofgem.gov.uk/publicationsand-updates/demand-side-response-discussion-paper

7. National Grid (2009) Policy brief: operating the system beyond 2020. Accessed on 10th December 2012. Available from: http://www.nationalgrid. com/NR/rdonlyres/45D855F7-32B6-41E5-9BD5-1B9A65DB9197/35114/ FactSheet2020S01.pdf

8. Committee on Climate Change (2008) Building a low-carbon economy - the UK's contribution to tackling climate change. Accessed on 10th December 2012. Available from: http://www.theccc.org.uk/pdf/TSO-ClimateChange.pdf

9. Pudjianto D, Djapic P, Aunedi M, Gan CK, Strbac G, Huang S, Infield D (2013) Smart control for minimizing distribution network reinforcement cost due to electrification. Energy Policy 52:76-84

10. Stromback J, Dromacque C, Yassin M (2011) Empower demand: the potential of smart meter enabled programs to increase energy and systems efficiency: a mass pilot comparison. A report by VaasaETT, Global Energy Think Tank. Accessed 28 Feb 2014; Available from: http://esmig.eu/sites/ default/files/empower-demand-report.pdf

11. Ofgem (2012) Scheme tariff tables. Accessed on 10th December 2012. http://www.ofgem.gov.uk/Sustainability/Environment/fits/tariff-tables/Pages/ index.aspx

12. Cherrington R, Goodship V, Longfield A, Kirwan K (2013) The feed-in tariff in the UK: a case study focus on domestic photovoltaic systems. Renewable Energy 50:421-426

13. McKenna E, Thomson M (2013) Photovoltaic metering configurations, feed-in tariffs and the variable effective electricity prices that result. IET Renewable Power Generation 7(3):1-11

14. British Gas 6th February 2012, Our tariffs. http://www.britishgas.co.uk

15. Kockar I, Papadaskalopoulos D, Strbac G, Pudjianto D, Galloway S, Burt G (2011) Dynamic pricing in highly distributed power systems of the future. In: Power and Energy Society General Meeting. IEEE, San Diego, pp 1-4

16. Roscoe AJ, Ault G (2010) Supporting high penetrations of renewable generation via implementation of real-time electricity pricing and demand response. Renewable Power Generation, IET 4:369-382

17. Allcott H, Mullainathan S (2010) Behavior and energy policy. Science 327:1204-1205

18. Team BI (2011) Behaviour change and energy use. Accessed on 10th December 2012. Available from: http://www.decc.gov.uk/assets/decc/11/ cutting-emissions/behaviour\%20change/2135-behaviour-change-andenergy-use.pdf

19. Shampanier K, Mazar N, Ariely D (2007) November/December, zero as a special price: the true value of free products. Marketing Science 26:742-757

20. Dellavigna S (2009) Psychology and economics: evidence from the field. Journal of Economic Literature 47:315-372

21. Kahneman D, Knetsch J, Thaler R (1990) Experimental effects of the endowment effect and the Coase theorem. Journal of Political Economy 96:1325-1348
22. Keirstead J (2007) Behavioural responses to photovoltaic systems in the UK domestic sector. Energy Policy 35:4128-4141

23. Bahaj AS, James $P$ (2007) Urban energy generation: the added value of photovoltaics in social housing. Renewable and Sustainable Energy Reviews 11:2121-2136

24. Dobbyn J, Thomas $\mathrm{G}$ (2005) Seeing the light: the impact of micro-generation on our use of energy. Accessed on 10th December 2012. Available from: http://www.sd-commission.org.uk/publications.php?id=239

25. McKenna E (2013) Demand response of domestic consumers to dynamic electricity pricing in low-carbon power systems. Thesis, Loughborough, Available from: https://dspace.Iboro.ac.uk/2134/12120

26. MoneySavingExpert.com (2012) So now I have a solar PV system how do I make the most of it? Accessed on 10th December 2012. http://forums. moneysavingexpert.com/showthread.php?t=2955406

27. Keirstead J (2006) Behavioural responses to photovoltaic systems in the UK domestic sector., Thesis, Oxford. Accessed on 10th December 2012. Environmental Change Institute. 410.www.jameskeirstead.ca/documents/ final_corrected_thesis.pdf

28. MoneySavingExpert.com (2012) Terms \& conditions. Accessed on 10th December 2012. http://www.moneysavingexpert.com/site/terms-conditions

29. DECC (2012) Feed-in tariffs. Accessed on 10th December 2012. http://www. decc.gov.uk/fits/

30. Green R, Vasilakos N (2010) Market behaviour with large amounts of intermittent generation. Energy Policy 38:3211-3220

31. Cox J (2009) Impact of intermittency: how wind variability could change the shape of the British and Irish electricity markets. Accessed on 10th December 2012. Available from: www.uwig.org/Impactoflntermittency.pdf

32. Renewable Energy Foundation (2012) Balancing mechanism wind farm constraint payments. Accessed on 10th December 2012. http://www.ref.org. uk/constraints/

33. Eirgrid, SONI (2012) 2011 Curtailment report. Accessed 4th July 2013. Available from: http://www.eirgrid.com/media/2011\%20Curtailment\% 20Report.pdf

34. Star A, Isaacson $M$, Haeg D, Kotewa $L$ (2010) The dynamic pricing mousetrap: why isn't the world beating down our door? In: ACEEE Summer Study on Energy Efficiency in Buildings, CA, USA ed. Anonymous ACEEE, USA, pp 257-268

35. Letzler R (2010) Using incentive preserving rebates to increase acceptance of critical peak electricity pricing. Center for the Study of Energy Markets Working Paper Series, CSEM WP 162R:1-67

36. Dütschke E, Paetz A (2013) Dynamic electricity pricing — which programs do consumers prefer? Energy Policy 59:226-234

37. Darby SJ (2012) Metering: EU policy and implications for fuel poor households. Energy Policy 49:98-106

doi:10.1186/2192-0567-4-13

Cite this article as: McKenna and Thomson: Demand response behaviour of domestic consumers with photovoltaic systems in the UK: an exploratory analysis of an internet discussion forum. Energy, Sustainability and Society 2014 4:13.

\section{Submit your manuscript to a SpringerOpen ${ }^{\odot}$ journal and benefit from:}

- Convenient online submission

- Rigorous peer review

- Immediate publication on acceptance

- Open access: articles freely available online

- High visibility within the field

- Retaining the copyright to your article

Submit your next manuscript at $>$ springeropen.com 